\title{
Schizophrene Wortkünstler und ihre tollkühnen Gedankensprünge
}

\section{Felix Schürch}

Dr. med., Facharzt für Allgemeine Innere Medizin, Mitglied FMH

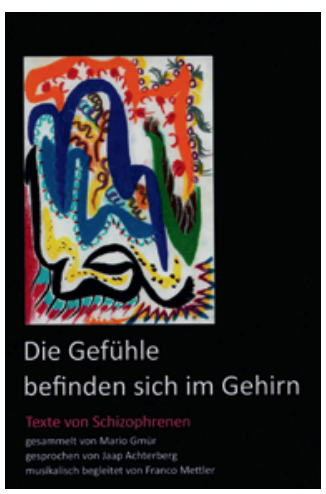

Mario Gmür (Hrsg.)

Die Gefühle befinden sich im Gehirn

Texte von Schizophrenen

Dozwil: EDITION SIGNAThUR; 2016.

48 Seiten, illustriert und mit CD. 18 CHF.

ISBN 978-3-906273-13-6

«Die Gefühle befinden sich im Gehirn, das aus weisser Substanz ist, von grauer Substanz bedeckt.» Zu lesen ist diese Feststellung in einem schmalen Buch mit 22 Texten von Schizophrenen. Die Erläuterungen zum Aufbau des Gehirns enden mit dem Satz: «Die Gefühle sind in der ganzen Substanz.» So verleiht dieser Text dem Begriff «Substanz» durch Wiederholung, Steigerung und Betonung unvermittelt eine neue Bedeutung - eine Bedeutung, welche über die Anatomie hinausgeht. In ähnlicher Weise verfahren andere Autoren in dieser Textsammlung mit anderen Begriffen. So erfahren wir, welche Nöte ein «Eskimo» im Kühlschrank erleidet. Wir werden aufgerufen, uns Gedanken zu unserem brutalen Umgang mit «Kopfsalat» zu machen. Und wir verfolgen den Tagesablauf eines Jungen und seine wechselhafte Beziehung zum "Schatten». Ganz zwanglos schaffen es viele dieser schizophrenen Wortkünstler, das Bekannte und Alltägliche aus dem gewohnten Zusammenhang herauszulösen und in einem neuen Licht erscheinen zu lassen.
Einige Autoren äussern sich weniger locker und spielerisch. Ein anklagender, fordernder Ton wird ange- schlagen, beispielsweise im Brief "An den Schweizer Bundesrat». Einige Autoren trumpfen mit grossen Ankündigungen auf. Im Brief an "Herrn Dr. X» wird zum Beispiel eine neue "Lichtgeschwindigkeitstheorie» verkündet. Mit grossem Pathos fordert der Entdecker sowohl Physiker und Astronomen als auch Laien zu einem "geistigen Zweikampf» heraus. Bei der Entschädigungssumme, welcher der Verlierer dem Gewinner schuldet, tönt es dann etwas profaner: Der Entdecker verspricht als Einsatz in diesem epochalen Duell sein fast neues Velo mit drei Übersetzungen und eine Taschenuhr. Oft werden grosse Themen in diesen kurzen Betrachtungen und Gedichten aufgegriffen, was sich bereits in den Überschriften ankündigt: «Die ewige Percussion» oder «Am Grenzübergang zur Wahrscheinlichkeit». Sozusagen aus dem Hinterhalt tauchen in der nächsten Zeile überraschende Wendungen und tollkühne Gedankensprünge auf. Das macht die Lektüre kurzweilig und unterhaltend. Und je nach Veranlagung des Lesers animieren die Briefe und Betrachtungen, Gedichte und Verse in dieser Sammlung zu eigenen neuronalen Purzelbäumen.

Der Herausgeber Mario Gmür hat diese bunten Wortschöpfungen herausgepflückt aus den Krankengeschichten seiner psychiatrischen Praxis. Gelesen von

\section{Die Texte waren Inspiration und Material für szenische Lesungen auf verschiedenen Kleinkunstbühnen in der Schweiz.}

Schauspielern übten die Texte in Vorlesungen bei den Studierenden eine unmittelbare Faszination aus. Die Texte waren Inspiration und Material für szenische Lesungen auf verschiedenen Kleinkunstbühnen in der Schweiz. Folgerichtig ist dem Buch eine CD mit der Aufnahme einer Aufführung in Baden beigelegt. Der Schauspieler Jaap Achterberg spricht die Texte, musikalisch begleitet von Franco Mettler. Zusammen mit diesem Tonträger - und mit den im Buch eingestreuten farbigen Zeichnungen - wird diese Publikation zum verlockenden Gesamtkunstwerk. Zum tragikomischen Spektakel. Hereinspaziert! 